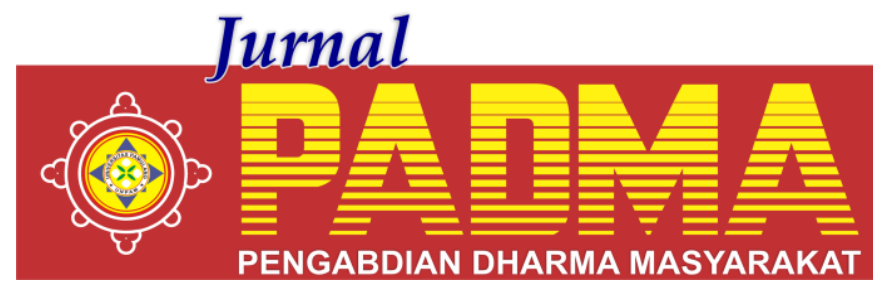

\title{
PENYULUHAN PENGELOLAAN KEUANGAN SEDERHANA SISWA SMK NEGERI 28 JAKARTA
}

\author{
${ }^{1 *}$ Ivantan, 2Puji Harjianto, ${ }^{3}$ Sutrisno, 4 Paeno, 5 Yanurianto \\ Universitas Pamulang, Tangerang Selatan, Banten, Indonesia \\ *dosen02504@unpam.ac.id
}

\begin{abstract}
Abstrak
Penyuluhan pengelolaan keuangan sederhana untuk meningkatkan knowledge siswa dalam hal mengelola keuangan sehari-hari maupun lingkup UMKM keluarga, hal ini bersama-sama kita ketahui bahwa manfaat pengetahuan pengelolaan keuangan ini sangatlah penting dalam peran Ekonomi masyarakat, karena dengan pemahaman pengelolaan keuangan yang baik akan meningkatkan kesadaran pada masyarakat bahwa pengelolaan keuangan yang buruk akan cukup berdampak pada siklus Ekonomi mereka. Tujuan dari penyuluhan pengelolaan keuangan sederhana ini untuk meningkatkan kapasitas dan kemampuan siswa dalam memahami pentingnya pengelolaan keuangan yang baik, hal ini dapat mereka praktekkan dalam kehidupan sehari-hari minimal dalam ruang lingkup keluarga dan lingkungan sekitar.
\end{abstract}

Kata Kunci: Pengelolaan Keuangan

\section{Abstract}

Counseling on simple financial management to increase student knowledge in terms of managing daily finances and the scope of family MSMEs, we know together that the benefits of this knowledge of financial management are very important in the role of the community's economy, because understanding good financial management will increase awareness. to society that poor financial management will have enough impact on their economic cycle. The purpose of this simple financial management education is to increase the capacity and ability of students to understand the importance of good financial management, which they can practice in their daily life at least within the scope of their family and environment.

\section{Keywords: Financial Management}

\section{PENDAHULUAN}

Kegiatan pengabdian masyarakat merupakan salah satu Tri Dharma Perguruan Tinggi Selain Pendidikan dan Penelitian, sesuai undang-Undang RI Nomor 20 Tahun 2003 tentang Sistem Pendidikan Nasional, pada Pasal 20 ayat 2 dinyatakan : "Perguruan Tinggi berkewajiban menyelenggarakan pendidikan, penelitian dan pengabdian masyarakat". Pada Pasal 24 ayat 2 disebutka"Perguruan tinggi memiliki otonomi untuk mengelola sendiri lembaganya sebagai pusat penyelenggaraan pendidikan tinggi, penelitian ilmiah, dan pengabdian masyarakat".

Pengabdian kepada masyarakat merupakan pelaksanaan pengamalan ilmu pengetahuan, teknologi dan seni budaya langsung pada masyarakat secara kelembagaan melalui metodologi ilmiah sebagai penyebaran Tri Dharma Perguruan Tinggi serta tanggung jawab yang luhur dalam usaha mengembangkan kemampuan masyarakat, sehingga dapat mempercepat laju pertumbuhan tercapainya tujuan pembangunan nasional.

Program pengabdian kepada masyarakat merupakan salah satu program yang wajib dilaksanakan, baik oleh dosen maupun oleh mahasiswa, dengan berlandaskan pada prinsipprinsip: motivasi pemenuhan kompetensi akademik, jiwa kewirausahaan (entrepreneurship), dan profesional serta kesehatan masyarakat khususnya anakanak calon penerus bangsa, sehingga dapat menghasilkan program pengabdian kepada masyarakat yang bermutu, relevan, dan sinergis dalam meningkatkan pemberdayaan masyarakat. 
Manajemen merupakan salah satu program studi di Universitas Pamulang. Program studi ini memiliki andil dalam mencetak lulusan yang berkarakter serta mampu bersaing di dalam dunia kerja, serta dapat berperan bagi pembangunan. Pengabdian kepada masyarakat adalah bentuk Kegiatan pengabdian masyarakat merupakan salah satu Tri Dharma Perguruan Tinggi Selain Pendidikan dan Penelitian, sesuai undang-Undang RI Nomor 20 Tahun 2003 tentang Sistem Pendidikan Nasional, pada Pasal 20 ayat 2 dinyatakan: "Perguruan Tinggi berkewajiban menyelenggarakan pendidikan, penelitian dan pengabdian masyarakat". Pada Pasal 24 ayat 2 disebutkan:"Perguruan tinggi memiliki otonomi untuk mengelola sendiri lembaganya sebagai pusat penyelenggaraan pendidikan tinggi, penelitian ilmiah, dan pengabdian masyarakat".

Pengelolaan keuangan yang baik dan benar terkadang masih menjadi hal yang sulit difahami oleh Sebagian masyarakat khususnya generasi muda. SMK Negeri 28 Jakarta yang berisi generasi muda dari berbagai kalangan dan latar belakang ekonomi ini juga sangat menyadari akan pentingnya hal tersebut, dimana terkadang apa yang mereka dapat dari pelajaran di sekolah kurang komprehensif dan tidak mendapatkan contoh konkret pada kehidupan sehari-hari.

Dari kondisi tersebut, mereka belajar dan mencari secara otodidak terkait pengetahuan pengelolaan keuangan yang baik dan benar serta yang mereka anggap mudah difahami secara komprehensif, hadirnya penyuluhan pengelolaan keuangan sederhana ini tentu menjadi hal yang sangat mereka tunggu dan mereka butuhkan, dimana adanya sharing knowledge dari para ahli dan pengalaman dibidangnya. Antusisas ini juga dirasakan dan disambut baik oleh pihak sekolah terutama guru-guru, mereka sangat terbantu untuk membentuk karakter siswa yang kuat dalam hal pengetahuan ekonomi khususnya pengelolaan keuangan yang sederhana, dengan harapan selain dapat menyusun perencanaan keuangan yang baik mereka juga mampu mempraktekan ilmu yang didapat juga menjadi motivasi untuk terus melanjutkan
Pendidikan ke jenjang yang lebih tinggi, karena timbulnya kesadaran bahwa tidak cukup jika mereka hanya menimba ilmu sampai jenjang Pendidikan SMK saja.

Kegiatan Pengabdian Kepada Kegiatan pengabdian kepada masyarakat dari tim dosen dan mahasiswa Universitas Pamulang hadir di lingkungan SMK Negeri 28 Jakarta, serta berbagi pengetahuan dan wawasan dengan bentuk penyuluhan yang menggunakan teknik group discussion untuk lebih dapat memahami teori yang disampaikan secara komprehensif. Penyuluhan yang bertujuan membentuk karakter siswa yang kuat dalam hal pengetahuan ekonomi khususnya pengelolaan keuangan yang sederhana, dengan harapan mereka dapat mempraktekan ilmu yang sudah mereka dapatkan sehingga dapat menyusun perencanaan keuangan yang baik.

\section{METODE}

Dengan menggunakan diskusi kelompok, penyuluhan ini mengedukasi untuk membentuk karakter siswa yang kuat dalam hal pengetahuan ekonomi khususnya pengelolaan keuangan yang sederhana, dengan harapan mereka dapat mempraktekan ilmu yang sudah mereka dapatkan sehingga dapat menyusun perencanaan keuangan yang baik.

Kebutuhan manusia dalam ilmu ekonomi bisa dikatakan tidak terbatas adanya. Semua keinginan ingin sekali terealisasi dengan mudah. Kondisi ini tentusaja tidak akan bisa terwujud tanpa adanya pengaturan keuangan yang baik.

Alasannya, dengan mengatur keuangan seseorang bisa memperioritaskan antara kebutuhan primer, skunder, dan tersier. Oleh sebab itulah pada PKM ini akan diberikan penyuluhan mengatur keuangan bagi anak, khususnya anak dalam usia sekolah (pelajar).

\section{HASIL DAN PEMBAHASAN}

Banyak siswa merasakan tekanan dalam finansial untuk saat ini dan masa depan. Lebih dari seperempat, atau sekitar 28 persen merasakan banyak kecemasan finansial sehingga berdampak dari kegiatan belajar yang sedang dijalani. Masalah keuangan membuat siswa mengalami stress 
dan memikirkannya terus-menerus, pola hidup konsumtif pada usaia remaja akan berdampak buruk juga dengan keuangan mereka. Dengan kecemasan yang berlebih, besar kemungkinan siswa malah mengambil keputusan yang salah. Seperti tidak sengaja menghabiskan uang.

Ditemukan masih kurangnya pemahaman dan pengetahuan para remaja khususnya siswa dalam mengelola keuangan mandiri, siswa yang memiliki kegiatan usaha dalam hal mengatur diri dan membuat perencanaan keuangan yang baik. Hal itu dikarenakan para anggota mayoritas masih belum memiliki pemahaman dan sikap dalam berorganisasi yang baik. Sehingga diperlukan penyuluhan mengenai pengelolaan keuangan sederhana. Agar siswa dapat megelola keuangan dengan baik, hal itu akan sangat membantu ketika seseorang yang menginjak masa dewasa awal, masa di mana secara psikologis jiwanya masih rentan untuk terpengaruh dan mudah berubah-ubah, hal utama yang menjadi konstentrasi adalah keuangan bagi para dewasa awal.Mengingat pengeluarannya juga akan besar karena gaya hidup pada masa ini lebih tinggi daripada anak-anak atau orang tua. Remaja yang berada pada masa ini mendapatkan pemasukan dari orang tua atau hasil bekerja. Sehingga harus dapat memanage keuangannnya dengan baik.

Masalah keuangan yang dihadapi siswa adalah pengeluaran lebih besar dibandingkan dengan uang bulanan yang didapat dari orangtua.Sebagai seorang siswa, sudah harus mulai melatih diri untuk bisa mandiri dan bisa mengatur keuangan sendiri tanpa campur tangan orangtua.Akan tetapi, masih banyak siswa yang kehabisan uang jajan sampai harus menahan lapar di akhir bulan.

Uang bulanan pemberian orang tua seringkali tidak bisa mencukupi semua kebutuhan dan memaksa siswa untuk mencari cara (biasanya pinjam uang ke teman) demi bertahan hingga bulan berikutnya. Siswa sangat konsumtif dalam berbelanjan, Tawaran diskon, apalagi dengan skema "potongan pada pembelian kesekian" mendorong seseorang untuk membeli barang-barang yang kurang esensial demi mengejar diskon. Alasannya, "suatu saat akan berguna" atau "kapan lagi dapat barang murah". Padahal setelah dihitung benar- benar-misalnya pada barang " $\mathrm{A}$ "perbedaan harga setelah mendapatkan diskon dengan sebelum diskon hanya berbeda sedikit saat membelinya satuan. Siswa seharusnya dapat belajar untukk lebij realistis pada jebakan-jebakan diskon yang ditawarkan. Tak lagi menjadi kalap, siswa akan lebih selektif pada barang yang benarbenar esensial, dengan atau tanpa diskon. Agar hal tersebut tidak terjadi, siswa perlu membuat anggaran keuangan dan disiplin mencatat keuangan setiap bulannya.

Sebagian siswa masih berpikir bahwa kegiatan mereka hanya sekadar belajar dan berpartisipasi dalam kegiatan sekolah yang tidak bisa menghasilkan uang.

Masalah keuangan siswa berikutnya adalah susahnya untuk menabung dan melakukan investasi dengan uang jajan bulanan. Dengan status siswa yang dimiliki terkadang membuat siswa berpikir santai dan merasa masih punya banyak waktu untuk mempersiapkan masa depan sehingga merasa tidak perlu rajin menabung. Padahal kebiasaan dari usia muda inilah yang akan menentukan kesuksesan financial mereka saat dewasa nanti.

Masalah keuangan siswa selanjutnya adalah tidak memiliki uang di saat-saat genting.Misalnya, tiba-tiba guru mewajibkan seluruh siswa untuk membeli peralatan praktikum yang mahal. Atau tiba-tiba siswa jatuh sakit dan harus dirawat, sementara tidak punya uang yang cukup.

Setiap orang tentu akan/telah melewati masa dewasa awal atau masa peralihan dari masa remaja. Masa dewasa awal terjadi saat usia kurang lebih 20 tahun. Saat memasuki masa tersebut, seseorang sudah mulai menemukan identitas dirinya. Banyak hal yang harus dipersiapkan seseorang untuk mmempersiapkan masa ini.

Berbagai macam perubahan juga terjadi pada diri seseorang yang sedang menginjak masa ini. Mulai dari perubahan fisik, mental, pola pikir, dan lainnya. Salah satu yang terjadi pada masa ini yaitu rasa ketergantungan akan berkurang dan berubah menjadi rasa mandiri.

Adapun beberapa pengaturan keuangan ini bisa dilakukan oleh pelajar. Baik berada di tingkat pendidikan SMK, SMP, atapun tingkat SD dan Mahasiswa. Semuanya 
bisa mengimplementasikan, dengan langkahlangkah sederhananya adalah sebagai berikut Menuliskan tentang rencana keuangan menjadi salah satu prioritas yang harus dilakukan bagi pelajar, agar dapat memaksimalkan pendapatan dan pengeluaran dengan baik. Rencana ini bisa dijalankan dalam jangka panjang dan pendek. Akan tetapi dari kesemua itu lebih baik membuat keduanya, alasannya dengan jalan inilah setiap orang akan fokus pada tujuan yang di inginkan.

Langkah kedua dalam mengatur keuangan yang baik bagi seorang pelajar ialah melakukan kontrol pada pengeluaran yang dianggap tidak penting. Kadangkala fenomena ini cukup menarik dan sulit dihindari ketika berada di dalam mall, bekumpul bersama teman, ataupun yang lainnya.

Tips selanjutnya dalam proses mengatur keuangan bagi pelajar ialah menghargai uang sekecil apapun, langkah ini bisa dijalankan misalnya saja dengan tidak membuang uang recehan seperti nilai 100 , 500, atapun 1000-an. Untuk mengantispasinya maka hal yang pelu dilakukan ialah dengan menyimpangnya dalam kaleng susu bekas, ataupun tempat lainya yang dapat menampung uang tersebut.

Langkah lainnya, yang bisa dijalankan dalam upaya mengatur keuangan ialah dengan mencari penghasilan tambahan. Pada saat inipeluang usaha untuk anak sekolah yang bisa di jalani, misalnya saja dari hal sederhana jika memiliki motor bisa ikut dalam komunitas ojek online. Atapun bisa juga dengan menjadi reseller baju, dan lain sebagainya. Dengan dukungan sosial media yang menjadi senjata kaum milenial saat ini, tentu banyak hal yang bisa dilakukan.

Dalam upaya melakukan pengelolaan keuangan yang baik, alangkah baiknya jika seorang pelajar membuat buku tabungan sendiri dengan tanpa sepengathuan orangtua. Alasannya agar suatu saat orangtua akan bangga dengan komitmenmu dalam menabung, sehingga sebagai orangtua pasti akan memberikan uang lebih dikemudian hari.

Setelah proses pengaturan dalam rencana keuangan dilakukan, tidak akan berhasil tanpa adanya komitmen melakukan apa yang sudah digarsikan, Oleh karena itulah sebagai gambaran coblah untuk disiplin pada diri sendiri.

Terakhir, setelah iktiar dilakukan. Maka langkah dalam mengatur keuangan bagi anak sekolah haruslah membiasakan diri untuk shodaqoh. Alasan hal ini diunagkpakan sebagai wujud keseriusan kta untuk membantu orang-orang yang membuatuhkan. Bahkan dalam beberapa istilah bijak mengatahkan jika sejatinya "Berbagai Tidak Akan Mengurangi".

\section{PENUTUP}

Acara kegiatan pengabdian kepada masyarakat ini dilaksanakan selama 3 hari, yaitu sebagai berikut.Pertama, pembukaan oleh Kepala Sekolah SMK Negeri 28 Jakarta kemudian dilanjutkan laporan dari Ketua Kegiatan sekaligus penjelasan pelatihan dan pembagian bahan paparan dan contoh laporan keuangan sederhana. Selanjutnya yaitu pemberian motivasi berwirausaha oleh narasumber. Kedua, kegiatan demonstrasi pembuatan laporan keuangan. Ketiga yaitu kegiatan penyuluhan mengenai bagaimana hasil teori tersebut dibuat sebagai dasar pengelolaan keuangan yang baik.

\section{DAFTAR PUSTAKA}

Agus Harjito, Martono. 2008. Manajemen Keuangan, edisi1. Yogyakarta: EKONISIA.

Anjayani, NS., Lutfi, AM., Suhartono, A., Sari, WI., Sunarsi, D. (2020). Pengaruh Perputaran Persediaan dan Rasio Perputaran Aktiva Terhadap Return on Invesment Pada PT Gudang Garam Tbk. TIN: Terapan Informatika Nusantara. Vol. Issue 4 Pages 171-176 Effendi, E., Affandi, A., \& Sidharta, I. (2016). Analisa Pengaruh Rasio Keuangan Model Springate Terhadap Harga Saham Pada Perusahaan Publik Sektor Telekomunikasi.

Ghozali, Imam. 2002. Statistik Non Parametrik Teori dan Aplikasi dengan Gitosudarmo, Indriyo, 1999, Manajemen Pemasaran, Edisi Pertama, Yogyakarta, BPFE

Haque, MG., Munawaroh, Sunarsi, D., (2020). Analysis of SMEs Culinary Marketing Strategy During Covid 19 Pancemic: A Study at "Sate Bebek 
Cilegon" Resto in Cilegon, Banten. International Journal of Education, Information Technology, and Others. Vol.3. Issue 2

Hermawati, R., Sugiyarti, L., Handayani, R., Sunarsi, D., Alfiah, S., \& Maddinsyah, A. (2020). The Effect of Trilogy Leadership Style and Organization Culture on School Performance: Evidence form Indonesian Senior High School. PalArch's Journal of Archaeology of Egypt/Egyptology, 17(6), 8512-8537.

Horne V. James dan John M Wachowicz. 2005. Prinsip-prinsip Manajemen Keuangan (Fundamental of Financial Management). $\quad$ Edisi 12. Diterjemahkan oleh Dewi Fitriasari. Jakarta: Salemba Empat.

I Made Sudana. 2011. Manajemen Keuangan Perusahaan Teori dan Praktik. Jakarta: Erlangga

K Nufus, H Supratikta, A Muchtar, D Sunarsi. (2020). Analysis of Financial Performance: Case Study of PT. X Employee Cooperative. Utopía Y Praxis Latinoamericana. Vol. 25. Pages 429-444

Maddinsyah, A., Hidayat, D., Juhaeri, J., Susanto, D., \& Sunarsi, D. (2020). Desain Formulasi Dan Implementasi Bisnis Strategik Dengan Pendekatan Business Model Canvas (BMC) Terintegrasi Kerangka Integrated Performance Management System (IPMS) Pada Koperasi Asperindo. Inovasi, 7(2), 67-76.

Manajemen Keuangan Untuk Siswa SMK 1 https://goo.gl/C3B1hJ

Manajemen Keuangan Untuk Siswa SMK 2 https://goo.gl/1NkaE2

Manik, C. D., Sarwani, K., Triyadi, E. S. W., \& Sunarsi, D. (2020). The Effect of PDCA Cycle on Service Quality, Innovation Capability, and Work Performance of Indonesian Private Universities. PalArch's Journal of Archaeology of Egypt/Egyptology, 17(6), 8462-8483.

Miranda Marquit. 10 April 2017. Essential Financial Skills to Learn Your Senior
Year of High School. Discover.com https://goo.gl/HnNxY7

Noryani, Y. B. G., Sari, W. I., Rosini, I., Munadjat, B., Sunarsi, D., \& Mahnun Mas' adi, G. (2020). Did ISO 45001, ISO 22000, ISO 14001 and ISO 9001 Influence Financial Performance? Evidence from Indonesian Industries. PalArch's Journal of Archaeology of Egypt/Egyptology, 17(7), 6930-6950.

Nurjaya, N., Sunarsi, D., Effendy, A. A., Teriyan, A., \& Gunartin, G. (2021). Pengaruh Etos Kerja Dan Disiplin Kerja Terhadap Kinerja Pegawai Pada Dinas Kehutanan Dan Perkebunan Kota Bogor. JENIUS (Jurnal Ilmiah Manajemen Sumber Daya Manusia), 4(2), 172-184.

Program SPSS Semarang: Badan Penerbit Universitas Diponegoro.

Sampurnaningsih, S. R., Andriani, J., Zainudin, Z. A. B. A., \& Sunarsi, D. (2020). The Analysis of Entrepreneurship Character and Entrepreneurship Intention among Students. PalArch's Journal of Archaeology of Egypt/Egyptology, 17(6), 8290-8303.

Senduk, S. 2004. Siapa bilang jadi karyawann gak bisa kaya;lim kiat praktis mengelola gaji agar bisa kaya. Elex mediakomputindo.Jakarta

Suhartono, A., Jati, W., \& Sunarsi, D. (2019). Pengaruh Earning Per Share Dan Return On Asset Terhadap Harga Saham Pada PT. Bank Negara Indonesia Tbk Periode 2009-2018. Jurnal Manajemen, Bisnis dan Organisasi (JUMBO), 3(3), 182-194.

Sunarsi, D. (2020). Implikasi Digitalisasi Umkm. Digitalisasi UMKM, 57. books.google.com

Yusni Nuryani, Denok Sunarsi. (2020). The Effect of Current Ratio and Debt to Equity Ratio on Deviding Growth. JASa (Jurnal Akuntansi, Audit dan Sistem Informasi Akuntansi) Volume 4, Issue 2, Pages 304-312. 